\title{
Family Medicine and the Life Course Paradigm
}

\author{
Timothy P. Daaleman, DO, MPH, and Glen H. Elder, Jr, PhD
}

A unique characteristic of family physicians is that they seek to understand individual patients within the context of their families and larger social environments. Unfortunately, the intellectual development of family medicine is hampered by the reliance on epidemiologic, health service, and biomedical paradigms that are limited in their contextual perspectives on patients' lives. However, another paradigm, that of the life course, represents an interdisciplinary framework that views persons in context over time. It provides an ecological understanding of individual people by examining phenomena at the nexus of social pathways, developmental or health trajectories, and social change. A life course paradigm provides a way of thinking about patients in both proximal (eg, lived lives and family) and distal (eg, health care system) contexts over a life span. Five core principles define the life course as a paradigmatic framework: (1) human development and aging as lifelong processes, (2) human agency, (3) historical time and place, (4) the timing of events in a life, and (5) linked lives. At the individual level, the life course orients physicians to the opportunities and constraints that frame the health care choices, plans, and initiatives of people who maintain health and also face illness. At the organizational level, the life course offers an intellectual infrastructure for the New Model of Family Medicine by depicting an idealized delivery system that may be longitudinally integrated. It also emphasizes health and illness trajectories by linking health and other service organizations that assist individuals at different stages of their lives. (J Am Board Fam Med 2007;20:85-92.)

"He does more than treat them when they are ill; he is the objective witness of their lives."

$$
\text { -John Berger }{ }^{1}
$$

Viewed from a philosophical perspective, family medicine can be considered a branch of science, but it is currently a branch without a well-defined orientation, often relying on epidemiologic, health service, and biomedical paradigms. ${ }^{2}$ From its nomenclature, family systems theory would seem to provide such a point of reference; however, most

This article was externally peer reviewed.

Submitted 26 January 2006; revised 4 October 2006; accepted 13 October 2006.

From the Department of Family Medicine, Program on Aging, Disability, and Long-Term Care, Cecil G. Sheps Center for Health Services Research (TPD), and Department of Sociology, Carolina Population Center (GHE), University of North Carolina at Chapel Hill, Chapel Hill, NC.

Funding: National Institute on Aging grant 1K23AG01033 (to TPD).

Corresponding author: Timothy P. Daaleman, DO, MPH, Department of Family Medicine, University of North Carolina at Chapel Hill, Campus Box 7595, Manning Drive, Chapel Hill, NC 27599-7595 (E-mail: tim_daaleman@med.unc.edu). family physicians do not consider this perspective to be central to the discipline. ${ }^{3-5}$ Family physicians appreciate the considerable impact of family on the health of their individual patients, but they share a much broader worldview that is inclusive of the social and cultural contexts that extend beyond the family unit. ${ }^{3,5-7}$ The "science" of the family, its role in health and illness, and its importance as a focus for the care of the individual has never been adequately developed or demonstrated in the history of the discipline. ${ }^{8}$

What are the alternatives? In this article, we introduce the life course as an interdisciplinary framework or paradigm that addresses the key issues that are distinctive of the family medicine world. This framework is grounded in a contextual perspective that views health and illness in light of the social and historical trajectories of individual persons. ${ }^{9}$ We conclude by assessing the potential contribution of the life course to the paradigmatic orientation of family medicine.

By paradigm, we refer to Thomas Kuhn's The Structure of Scientific Revolutions. ${ }^{10}$ Kuhn argues that science does not develop by individual discoveries and inventions; advancement occurs only after a 
defined scientific community agrees on a set of shared assumptions regarding the subject matter at hand. ${ }^{10}$ Once these assumptions have been made and are no longer questioned, they become embedded within the scientific mind and represent a received set of beliefs for members of a discipline. ${ }^{10}$ This basic set of beliefs, or first principles, is termed a paradigm and constitutes a worldview that defines the perceived nature of the world, the individual person's place in it, and the range of possible relationships to the world and its constituent parts. ${ }^{11} \mathrm{We}$ consider the life course a paradigmatic framework.

\section{Lives As a Framework in Life Course Theory}

Family physicians often care for the same patient over many years, and they do so across changing times in the life of that patient (eg, health and illness) and in changing eras (eg, economic cycles) and places. ${ }^{8}$ Over these periods of care, related changes occur in the lives of patients, their family members, as well as in the life of the physician who provides care. A unique characteristic of family physicians, according to Ian McWhinney, is that they seek to understand individual patients (ie, persons) within the context of their families and larger social environments. ${ }^{2}$ The life course provides a way of relating these persons to their contexts over their life span.

A foundation on which to frame and articulate an understanding of physician and patient, in particular, begins with the social role or relationship theories that provided one of the earliest perspectives on lives. It is one strand of today's life course theory. ${ }^{12-14}$ This perspective describes the socialization of people into and out of social roles (eg, parent, student) that are accompanied with a set of proscriptive and prescriptive expectations. ${ }^{13} \mathrm{~Pa}-$ tients may occupy a sick role, which can release them from their usual obligations and responsibilities, such as work or parenting. ${ }^{15}$ However the sick role is not isolated to a uniform set of expected behaviors and attitudes but is contextualized by a lived history across different periods of the life span. ${ }^{16}$ Consider the older patient with congestive heart failure, who is generally more readily recognized and accepted by health care providers in the sick role compared with a younger patient with fibromyalgia, although both patients may have similar cycles of disability and physical functioning.
The transition from one family generation to the next across the life span depicts a life cycle in this way of thinking about lives. Children mature into adulthood, give birth to their own children, enter into middle years, late life, and retirement, and are replaced by their offspring. This human life cycle in a community, or in a larger society, portrays the role sequences of "linked lives," but sequences do not indicate precisely where people are in their lives. First-time parents, for example, may be 20 or 70 years old.

Social roles also fail to locate people in historical time and place. Role-theoretical perspectives on lives, such as role change and life cycles, are limited in their ability to conceptualize lived experiences because they are "timeless"; that is, they fail to locate people within their lives and the larger social-historical context. Life course theory fills this void by incorporating concepts of age and temporality. ${ }^{17,18}$ These concepts recognize that age has multiple meanings and interpretations (eg, historical time, social time, biological time) and their lives vary in the timing and scheduling of events along the life course. ${ }^{18}$ Role relationships and the meanings of age jointly locate people in their lives and social-historical contexts. Most clinicians are familiar with the concept of biological time, which depicts the physiologic manifestations of a body that changes over time. In contrast, social age tells us where people are in their lives, whether young adult or middle age. Historical time, derived from birth year, places people into a historical era, such as children growing up during the Great Depres$\operatorname{sion}^{19}$ or adults who came of age during the 1960s.

Timing and the onset of key events also locate people along the life course and reveal the "variability" of lives. Some people complete their education early in life, whereas others do so in late middle age, after their children have left home. The health effects of life events and transitions often depend on when they occur, as illustrated when widowhood and bereavement occur either early or later in life. ${ }^{20}$ In addition, ill-timed events in one person's life are not completely autonomous but affect others who are part of the larger social environment. Consider the impact of an unanticipated birth of a child to a teenage mother on the employment status and child-rearing timetable of the entire family.

The contextual aspect of the life course comes from perspectives on role relationships and age, the 
2 intellectual strands of the life course as a paradigmatic framework. A third strand focuses on lifespan concepts of development and aging, drawing on contributions from psychology and sociology. Concepts such as life review and autobiographical memory emphasize the importance of narrative and memoir accounts within lived lives, ${ }^{21}$ whereas perspectives on personal agency view people as central actors and producers of their own development. ${ }^{22}$ In the United States, patient-centered movements, such as end-of-life care and complementary and alternative medicine, can be viewed as attempts by patients to reclaim their own agency within a health care system that is increasingly depersonalized and grounded in technology. ${ }^{23}$

A theoretical orientation on the life course emerged from these traditions: social relations (ie, roles and life cycles), the meanings of age, and concepts of life span development. Social and developmental trajectories and transitions are basic concepts of this new perspective. Trajectories are sequences or long-term patterns within a focal area (eg, health, family, or work situations) and are formed by linking states (eg, poverty, health status) and transitions across successive years. ${ }^{24}$ Trajectories are embedded in social pathways defined by social institutions and relationships that provide social support. Life trajectories can be charted by linking events or states across successive years (for example, the states of employment, earnings, and health). ${ }^{25}$ Each trajectory, whether social or developmental, is marked by a sequence of life transitions and changes in state.

Health trajectories differ from other longitudinal health assessments by focusing on sequences of health transitions across time and viewing the patient's experience of health and illness longitudinally rather than as episodes. Such an approach provides an illuminating way to frame and communicate context within clinical settings. ${ }^{26}$ Consider the concept of trajectories of dying, which has received renewed attention in understanding the progression of serious chronic illness to death. ${ }^{27}$ Four such trajectories—sudden death, terminal illness, organ failure, and frailty - vary in the timing and progression of health events, such as functional decline, but collectively provide a framework for understanding and articulating the last phase of life for both patients and physicians. ${ }^{28}$

Trajectories are made up of transitions (eg, decline in health status). Transitions, in turn, acquire meaning within trajectories and are changes in state that are discrete and have an identifiable beginning and end. States and transition lead to the concept of duration, or the waiting times or spells between a change in state. A duration has many implications and meanings for the life course and health: duration of marriage is linked to marital permanence and the potential for stable economic and emotional support and, subsequently, improved health ${ }^{29}$; duration of joblessness is correlated with the risk of becoming unemployable, experiencing poor health, and disability. ${ }^{30}$ In all these cases, duration typically stands for an explanatory process that is not well understood.

When a trajectory, with its transitions, changes course and places people in new environments, it is referred to as a turning point. ${ }^{31}$ Turning points are individual or institutional sentinel moments that result in a change of direction along one's life course. ${ }^{32}$ For example, a chronically ill patient who declines further hospitalization or aggressive medical care has reached a turning point. The probable subsequent decline in health and functional status and entry into long-term care would constitute both a trajectory and a turning point. Personal and social trajectories are embedded in social relationships (eg, the family network, patient-physician relationship), which provide a more comprehensive understanding of factors that potentially affect a patient's experience of health and illness.

Concepts of trajectory and transition are central themes in lived lives, representing both the long and short perspective on analytic scope. ${ }^{33}$ These lives take place over an extended span of time, a social trajectory of work or marriage or a developmental trajectory of illness or health. Transitions are always embedded in trajectories, which gives them distinctive form and meaning. In turn, trajectories, both social and developmental, are worked out in established social pathways, defined by institutions and populations. Chronic illness trajectories, for example, are largely the province of older adults and are shaped by institutions within a health care delivery system that is predominantly organized around acute care. ${ }^{34}$

The life course paradigm can be viewed as an orientation that views persons within contexts over time. As such, it provides a foundation for disciplines seeking to promote an ecological understanding of people at the nexus of social pathways, developmental trajectories, and social change. ${ }^{35}$ As 
noted, 5 general principles, derived from research in the social and behavioral sciences, provide guidance for such pursuits.

\section{Paradigmatic Principles of the Life Course}

Life course principles direct attention to individual choice and decision making, endorse an awareness of larger social and historical contexts, and promote an understanding of the timing of events and role change. They also view human lives within a matrix of relationships with significant others. Life course principles guide inquiry by enabling a holistic understanding of lives over time and across changing social contexts. ${ }^{35}$ They are (1) human development and aging as lifelong processes, (2) human agency, (3) historical time and place, (4) timing, and (5) linked lives. ${ }^{9}$

The principle of lifelong development and aging embraces a longitudinal, often intergenerational, perspective that links early life influences with events and outcomes in subsequent years. ${ }^{36} \mathrm{An}$ emerging body of research on later life psychosocial sequelae in pediatric cancer survivors is representative of this principle. ${ }^{37}$ Human agency views people as active participants who construct their own life courses through the choices and actions they take, given the opportunities and constraints of history and social circumstances. ${ }^{22,38}$ The construction and maintenance of meaning is of primary importance to chronically ill patients ${ }^{39}$ and to those approaching the end of life. ${ }^{40}$

The principle of timing highlights the developmental antecedents and consequences of behavior patterns, life events, and transitions that vary according to their timing in a person's life. ' The meaning of a family member's death varies by stage of the life course-note the meaning of a child's death versus that of an elderly grandparent. Expectations on when life events should occur are implicit in the principle of timing and are normative in areas such as childbearing and family life, and those around the beginning and end of life. ${ }^{41}$ As a result, patients may view themselves as synchronous ("on-time") or asynchronous ("off-time") with these expectations. This principle is illustrated by variations in the timing of menarche, whether early or late, and by a high-school student who unexpectedly finds herself pregnant and in a "too early" age group according to the family formation timetable of her birth cohort. Events that come too early, such as the loss of a parent, seem to have more severe emotional consequences than an on-time event.

Linked lives refers to the interdependence and network of shared relationships that surround individual lives. The concept of "social convoy," a grouping of significant others (eg, important family members, long-time friends) across different life periods, ${ }^{16}$ conveys a longitudinal and fluid aspect that is less readily achieved by social support or family network constructs. ${ }^{42}$ This concept is also more inclusive than the family unit because it captures the support network accompanying the patient. It places the physician within the context of a shared relationship with the patient as well.

Both individual lives and social convoys are located in a specific historical time and place, another core life course principle. The individual life course is embedded in and shaped by the historical times and places that a patient experiences over a lifetime. ${ }^{9}$ Consider the social and economic effects of the current AIDS epidemic on African children. Homelessness, migration, malnutrition, and reduced access to health care and education are staggering problems that have greatly increased the probability of illiteracy, poverty, and chronic illness in subsequent adulthood for this population. ${ }^{43}$ These effects can be viewed as historical and ecologic constraints that limit the range of potential opportunities and choices along the life course of these children.

According to the Institute of Medicine, the major role of primary care is to integrate the health care experience by providing accessible health care services, developing a sustained partnership with patients, and practicing within the context of family and community. ${ }^{44}$ Multiple levels of the life course provide a way for family physicians to understand patients who experience health and illness and receive health care within proximal (eg, family) and distal (eg, health care system) contexts over time. Extending across these levels are institutionalized pathways that establish a context in which people make choices, plans, and initiatives about the health and illness that affect their lives. ${ }^{35}$

\section{Family Physicians and the Life Course}

The life course has gained wide acceptance across multiple disciplines, enriching our understanding of aging and gerontology, criminal justice, devel- 
Table 1. Organizing Concepts and Principles in the Life Course

\begin{tabular}{|c|c|}
\hline Term & Definition \\
\hline Trajectory & $\begin{array}{l}\text { Sequences or long-term patterns within a } \\
\text { focal area (eg, health, family, or work } \\
\text { situations) that are embedded in social } \\
\text { pathways and defined by social } \\
\text { institutions and interpersonal } \\
\text { relationships. }\end{array}$ \\
\hline Transition & $\begin{array}{l}\text { Changes in state that are discrete, acquire } \\
\text { meaning within trajectories, and have an } \\
\text { identifiable beginning and end. }\end{array}$ \\
\hline Turning point & $\begin{array}{l}\text { Individual or institutional sentinel moments } \\
\text { that result in a change of direction along } \\
\text { one's life course. }\end{array}$ \\
\hline Linked lives & $\begin{array}{l}\text { The interdependence and network of shared } \\
\text { relationships that surround individual } \\
\text { lives. }\end{array}$ \\
\hline Social convoy & $\begin{array}{l}\text { A grouping of significant others (eg, } \\
\text { important family members, long-time } \\
\text { friends) across different life periods. }\end{array}$ \\
\hline Timing & $\begin{array}{l}\text { The developmental antecedents and } \\
\text { consequences of behavior patterns, life } \\
\text { events, and transitions that vary according } \\
\text { to their chronological location in a } \\
\text { person's life. }\end{array}$ \\
\hline $\begin{array}{l}\text { Human } \\
\text { agency }\end{array}$ & $\begin{array}{l}\text { Views people as active participants who } \\
\text { construct their own life courses through } \\
\text { the choices and actions they take, given } \\
\text { the opportunities and constraints of } \\
\text { history and social circumstances. }\end{array}$ \\
\hline
\end{tabular}

opmental psychology, and social epidemiology. ${ }^{45}$ And we believe it is relevant and applicable to family medicine today, as revealed by the Future of Family Medicine (FFM) project. The FFM articulates a primary role for family physicians as medical providers who humanize the health care experience by promoting a more contextual understanding of the patient. ${ }^{46}$ Contextual features of the social and physical environment influence the health of those exposed to it and, as such, are central to humanizing the health care experience. ${ }^{47}$

The life course offers a paradigmatic grounding to family medicine, a discipline that is attempting to understand contextual factors (Table 1). Life course thinking relates to the tradition of family physicians who provide care within the context of their communities; they are looked on as physicians who know their patients over time and across the generations. ${ }^{8,48}$ At a philosophical level, the life course fixes the clinical gaze of family physicians beyond the patient as member of a family unit to the patient who is a traveler along the life course. This suggests a role for the family physician as patient historian and interpreter, and health care guide and advocate along the trajectories, transitions, and turning points that accompany health and illness.

How would physicians, who are influenced by the life course perspective, relate to their patients, their health care colleagues, and the health care system, differently than today's family physician? Fundamentally, life course principles would direct the physician's attention to the contextual factors that affect patient choices, plans, and initiatives regarding their health and health care. The New Model of Family Practice, described in the FFM project, provides some practical applications to this new way of thinking. For example, the New Model endorses an ongoing examination of patient care data and the solicitation of patient feedback (eg, satisfaction with care) as quality indicators. ${ }^{3}$ In such a model, physicians with a life course framework would gather these data and feedback to ascertain the age-related elements of healthy adaptations, such as self-efficacious health behaviors in adolescents (eg, smoking cessation, drug and alcohol prevention $)^{38}$ and sustained functional status and enhanced quality-of-life in chronically ill older adults, ${ }^{49,50}$ as patient-centered indices of quality.

Life course health records within the New Model would depict patient trajectories, transitions, and turning points by determining sequences of health and illness across time (eg, change in health status, entry into assisted living or long-term care), and the patient's experience of health and illness longitudinally rather than as episodic events (eg, acute hospitalizations, office visits). In addition, health records could also account for place effects, which are characteristics of the social and physical environment, ${ }^{51}$ by using geographic information systems $^{52}$ to capture and understand features of the local environment that influence health and health care, such as poverty and unemployment rates, population density, and the distribution of health services in a defined area. ${ }^{47}$

Physicians of the life course would occupy a central, integrated role in relation to their subspecialty and other health care colleagues by using their contextual knowledge of the patient to help outline care options and facilitate decision making within and across all health care settings. ${ }^{53}$ For example, life course-oriented physicians would be prepared to work out the pathways of chronic care with their patients and colleagues at turning points, those individual sentinel moments that result in a 
change of direction (eg, entry into long-term care). They would do so by recognizing and guiding their patients through the institutional opportunities and constraints that frame the health care choices, plans, and initiatives of those who face illness, disability, and sometimes death.

From a systems perspective, a major recommendation of the FFM project promotes changing the organization and delivery of care through the New Model. It calls on family physicians to manage relationships, information, and processes of care in a reintegration of patient, physician, and practice. ${ }^{3}$ In addition, the New Model's emphasis on quality, described earlier, is congruent with a report from the Institute of Medicine, which recommends that the Centers for Medicaid and Medicare increase payments to providers who deliver high-quality care and consider replacing fee-for-service Medicare with a reimbursement and organizational structure focused on quality chronic illness care. ${ }^{545}$

In response, the New Model would position physician practices as a "medical home," with responsibilities for delivering quality medical care, coordinating care across health venues, providing health education, and supporting family caregivers. ${ }^{355}$ Life course physicians would be intellectually grounded and trained to improve the health of a defined population over the entire life course within the medical home. Within an idealized delivery system, a life course medical home would be longitudinally integrated, with a focus on minimizing developmental risks, such as poor diet, and optimizing health development trajectories, not only by linking health services but also by relating all organizations that serve people at different stages of their lives. ${ }^{48}$

Life course theory can also establish family medicine at the forefront of an emerging translational research agenda, where organizing and integrating multiple biological and social factors in a conceptual framework requires a systemic, longitudinal perspective. For example, rapid advances in basic and clinical science are identifying the complex genetic, metabolic, psychosocial, and environmental factors that contribute to obesity and its comorbid conditions, such as diabetes mellitus. ${ }^{56}$ By using the principles of human agency, linked lives, and lifelong human development and aging, family medicine investigators can frame research questions relevant to obesity studies. ${ }^{57}$ Lifelong development and aging orient clinical inquiry to the importance of early life influences (eg, learned eating behaviors, childhood obesity) on subsequent outcomes (eg, adult obesity, development of diabetes). Potential interventions to reduce obesity in children would need to account for the social ties and influence of parents and other family members, the linked lives along this period of the life course, as well as the cognitive dimensions of agency beliefs (eg, sense of self, self-esteem).

\section{Final Comments}

Family medicine has lacked a set of first principles and is now at a turning point in its own life course, as the field seeks to reinvent itself and re-establish its role within a changing US health care system. ${ }^{8}$ However, it shares a common historical timeline with the development of the life course with remarkable symmetry in both language and perspective. The intellectual history of family medicine is rooted in a commitment to people rather than to a body of knowledge. ${ }^{2,58}$ As such, it requires an orientation that conceptualizes, integrates, and ultimately humanizes the health and illness experience of patients who live their lives within a specific historical time and place. ${ }^{6}$ Family medicine also requires a way to articulate the world view of physicians who gather, interpret, and share these events with patients in continuous healing relationships. ${ }^{59}$ At the intersection of contexts, historical, social, and biographical, resides the life course of interdependent lives, providing a potential paradigmatic framework to further this endeavor.

We are grateful to Donald Pathman, John Frey, and Larry Green for their helpful comments on earlier versions of this article.

\section{References}

1. Berger J. A fortunate man: the story of a country doctor. New York: Random House; 1967.

2. McWhinney IR. A textbook of family medicine. New York: Oxford University Press; 1989.

3. Future of Family Medicine Leadership Project. The Future of Family Medicine: A Collaborative Project of the Family Medicine Community. Ann Fam Med 2004;2:S3-32.

4. Huygen FJA. Family medicine, the medical life history of families. New York: Brunner/Mazel; 1978.

5. Frey JJ. GP to FP to GP? Fam Med 2003;35:671-2.

6. Stange KC, Miller W, McWhinney I. Developing a knowledge base of family practice. Fam Med 2001; 33:286-97. 
7. Starfield B. Primary care: balancing health needs, services, and technology. New York: Oxford University Press; 1998.

8. Green LA, Graham R, Frey JJ, Stephens GG. Keystone III. The role of family practice in a changing health care environment: a dialogue. Washington, DC: The Robert Graham Center and the American Academy of Family Physicians; 2001.

9. Elder GH, Johnson MK. The life course and aging: challenges, lessons, and new directions. In: Settersten RA, editor. Invitation to the life course: toward new understanding of later life, part II. Amityville, NY: Baywood; 2002. p. 49-81.

10. Kuhn TS. The structure of scientific revolutions. 2nd ed. Chicago: University of Chicago Press; 1970.

11. Guba EG, Lincoln YS. Competing paradigms in qualitative research. In: Denzin NK, Lincoln YS, editors. Handbook of qualitative research. Thousand Oaks (CA): Sage Publications; 1994. p. 105-17.

12. Kertzer DI. Generation as a sociological problem. Ann Rev Sociol 1983;9:125-49.

13. Clausen JA. A historical and comparative view of socialization theory and research. In: Clausen JA, editor. Socialization and society. Boston: Little, Brown \& Company;1968. p. 18-72.

14. Brim OG, Wheeler SA. Socialization after childhood: two essays. New York: Wiley; 1966.

15. Mechanic D. Medical sociology. New York: Free Press; 1978.

16. Antonucci TC, Akiyama H. Convoys of social relations: family and friendships within a life span context. In: Blieszner R, Bedford VH, editors. Handbook of aging and the family. Westport (CT): Greenwood Press; 1995. p. 355-371.

17. Riley MW, Hess BB, Bond K. Aging in society: selected reviews of recent research. Hillsdale (NJ): L. Erlbaum Associates; 1983.

18. Neugarten BL, Neugarten DA. The meanings of age: selected papers of Bernice L. Neugarten. Chicago: University of Chicago Press; 1996.

19. Elder GH. Children of the Great Depression: social change in life experience. 25th anniv ed. Boulder (CO): Westview Press; 1999.

20. Wortman CB, Silver RC. Successful mastery of bereavement and widowhood: a life-course perspective. In: Baltes PB, Baltes MM, editors. Successful aging: perspectives from the behavioral sciences. New York: Cambridge University Press; 1990.

21. Thomas WI, Znaniecki F. The Polish peasant in Europe and America. New York: Dover Publications; 1958.

22. Clausen JA. American lives. New York: Free Press; 1993.

23. Daaleman TP. Religion, spirituality, and the practice of medicine. J AM Board Fam Pract 2004;17:370-6.

24. Duncan GJ, Brooks-Gunn J, Yeung YW, Smith JR. How much does childhood poverty affect the life chances of children? Am Sociol Rev 1998;63:40623.

25. Giele JZ, Elder GH. Methods of life course research: qualitative and quantitative approaches. Thousand Oaks (CA): Sage Publications; 1998.

26. Clipp EC, Pavalko EK, Elder GH. Trajectories of health: in concept and empirical pattern. Behavior, Health, and Aging 1992;2:159-79.

27. Lunney JR, Lynn J, Hogan C. Profiles of older medicare decedents. J Am Geriatr Soc 2002;50:1108-12.

28. Field MJ, Cassel CK. Approaching death. Washington DC: National Academy Press; 1997.

29. Sherbourne CD, Hays RD. Marital status, social support, and health transitions in chronic disease patients. J Health Soc Behav 1990;31:328-43.

30. Theorell T. Working conditions and health. In: Berkman LF, Kawachi I, editors. Social epidemiology. New York: Oxford University Press; 2000.

31. Sampson RJ, Laub JH. Crime in the making: pathways and turning points through life. Cambridge (MA): Harvard University Press; 1993.

32. Clausen JA. Life reviews and life stories. In: Giele JZ, Elder GH, editors. Methods of life course research. Thousand Oaks (CA): Sage Publications; 1998. p. 189-212.

33. Elder GH. Perspectives on the life course. In: Elder $\mathrm{GH}$, editor. Life course dynamics. Ithaca (NY): Cornell University Press; 1985.

34. Kane RL, Priester R, Totten AM. Meeting the challenge of chronic illness. Baltimore: Johns Hopkins University Press; 2005.

35. Elder GH, Johnson MK, Crosnoe R. The emergence and development of life course theory. In: Mortimer JT, Shanahan MJ, editors. Handbook of the life course. New York: Kluwer; 2003.

36. Amick BC, McDonough $\mathrm{P}$, Chang $\mathrm{H}$, Rogers $\mathrm{WH}$, Pieper CF, Duncan G. Relationship between allcause mortality and cumulative working life course psychosocial and physical exposures in the United States labor market from 1968 to 1992. Psychosom Med 2002;64:370-81.

37. Ross L, Johansen C, Dalton SO, Mellemjkaer L, et al. Psychiatric hospitalizations among survivors of cancer in childhood or adolescence. N Engl J Med 2003;349:650-7.

38. Bandura A. Self-efficacy, the exercise of control. New York: WH Freeman; 1997.

39. Charmaz K. The self as habit: the reconstruction of self in chronic illness. Otjr-Occupation Participation and Health Win 2002;22:31S-41.

40. Daaleman TP, VandeCreek L. Placing religion and spirituality in end-of-life care. JAMA 2000; 284:2514-7.

41. Wass H, Neimeyer RA, editors. Dying: facing the facts. 3rd ed. Washington DC: Taylor \& Francis; 1995. 
42. Broadhead WE, Gehlbach SH, DeGruy FV, Kaplan BH. The Duke-UNC functional social support questionnaire. Med Care 1988;26:709-23.

43. Foster G. Supporting community efforts to assist orphans in Africa. N Engl J Med 2002;346:1907-9.

44. Donaldson MS, Yordy KS, Lohr KN, Vanselow NA. Primary care: America's health in a new era. Washington DC: Institute of Medicine; 1996.

45. Mortimer JT, Shanahan MJ. Handbook of the life course. New York: Kluwer Academic; 2003.

46. Green LA, Graham R, Bagley B, et al. Task Force 1: report of the task force on patient expectations, core values, reintegration, and the new model of family medicine. Ann Fam Med 2004;2:S33-50.

47. Macintyre S, Ellaway A. Ecological approaches: rediscovering the role of the physical and social environment. In: Berkman LF, Kawachi I, editors. Social epidemiology. New York: Oxford University Press; 2000.

48. Halfon N, Hochstein M. Life course health development: an integrated framework for developing health, policy, and research. Milbank Q 2002;80: 433-79.

49. Stewart AL, Greenfield S, Hays RD, et al. Functional status and well-being of patients with chronic conditions. Results from the Medical Outcomes Study. JAMA 1989;262:907-13.

50. Stange KC. The paradox of the parts and the whole in understanding and improving general practice. Int J Qual Health Care 2002;14:267-8.

51. Berkman LF, Kawachi I. Social epidemiology. New York: Oxford University Press; 2000.

52. Ricketts TC. Geographic information systems and public health. Annu Rev Public Health 2003;24:1-6.

53. Weiner SJ, Barnet B, Cheng TL, Daaleman TP. Processes for effective communication in primary care. Ann Intern Med 2005;142:709-14.

54. Institute of Medicine. Leadership by example: coordinating government roles in improving health care quality. Washington DC: National Academies Press; 2002.

55. Wolff JL, Boult C. Moving beyond round pegs and square holes: restructuring Medicare to improve chronic care. Ann Intern Med 2005;143:439-45.

56. Yanovski JA, Yanovski SZ. Treatment of pediatric and adolescent obesity. JAMA 2003;289:1851-53.

57. Ferraro KF, Kelley JG. Cumulative disadvantage and health: long-term consequences of obesity. Am Sociol Rev 2003;68:707-29.

58. Stephens GG. The intellectual basis of family practice. Tucson (AZ): Winter Publishing Company; 1982.

59. Institute of Medicine, Committee on Quality of Health Care in America. Crossing the quality chasm: a new health system for the 21st century. Washington DC: National Academy Press; 2001. 